\title{
O comportamento das línguas românicas em relação ao parâmetro do sujeito nulo
}

\author{
Juliana Esposito MARINS * \\ Humberto SOARES DA SILVA **
}

Resumo: Estudos recentes, associando pressupostos da Teoria de Princípios e Parâmetros e da Sociolinguística, vêm demonstrando que o PB está passando por um processo de mudança quanto à marcação do Parâmetro do Sujeito Nulo. Para avaliar a mudança, é necessário situá-lo entre as outras línguas, para saber se suas características realmente se afastam das de línguas de sujeito nulo. Investigou-se o comportamento da fala culta de uma variedade do italiano e de duas do espanhol. Os resultados confirmam a hipótese de que o PE, o italiano e o espanhol compartilham características já não/pouco existentes no PB, como a não expressão do sujeito, apesar de apresentarem certas particularidades. Tais resultados confirmam a mudança no PB.

Palavras-chave: Parâmetro do sujeito nulo; Italiano; Espanhol.

Abstract: Recent studies, with Principles and Parameters and Sociolinguistics' presuppositions, have showed that Brazilian Portuguese (BP) is changing its setting concerning to Null Subject Parameter. To analyze this change, it is necessary to situate BP between other languages, which can help us to know if its characteristics are really distant from the null subject languages.

* Mestre em Letras (Letras Vernáculas) pela Universidade Federal do Rio de Janeiro.

** Mestre em Letras (Letras Vernáculas), em 2006, pela Universidade Federal do Rio de Janeiro, onde atua como docente. Contato: humbertosoares@hotmail.com. 
We examined the cultured speech of a variety of Italian and two varieties of Spanish. The results confirm our hypothesis that European Portuguese, Italian and Spanish share features that do not exist in BP anymore, or exist with a low frequency, like covert subjects, despite they have some peculiarities. These results confirm that a change is in progress in BP.

Keywords: Null subject parameter; Italian; Spanish.

\section{Introdução}

Os estudos sobre a representação do sujeito pronominal vêm encontrando terreno fértil diante dos indícios de que o português brasileiro (PB) está se afastando das demais línguas românicas na marcação do Parâmetro do Sujeito Nulo (PSN). O $\mathrm{PB}$, ao contrário do português europeu (PE), espanhol e italiano, apresenta um comportamento que permite afirmar que estamos diante de uma mudança paramétrica de língua [ + sujeito nulo] para [- sujeito nulo]. Estudos recentes (DUARTE, 1993; 1995; 2003) mostraram que, no PB, a redução do quadro pronominal e, consequentemente, do paradigma flexional do verbo - que levou a um paradigma funcionalmente empobrecido (com apenas três oposições), nos termos de Roberts (1993) - parecem ter desencadeado tal mudança.

Se, por um lado, já contamos com evidências quantitativas e qualitativas a respeito do comportamento do $\mathrm{PB}$, por outro, tais resultados tomam como referência propriedades de línguas apontadas na literatura gerativista como prototipicamente de sujeito nulo, tais como italiano e espanhol. Faltam-nos trabalhos sobre essas línguas usando o mesmo quadro teórico-metodológico dos estudos sobre PB, ponto motivador das análises de Duarte (1995) para o PE. A emergência desses trabalhos abriu caminho para análises de demais línguas românicas, com o intuito de verificar como se comportam e até que ponto apresentam comportamentos semelhantes. 
O objetivo deste trabalho é investigar a representação do sujeito pronominal em uma variedade de italiano standard ${ }^{1} \mathrm{e}$ em variedades da fala culta ${ }^{2}$ do espanhol para comparar com os resultados já obtidos para $\mathrm{PE}$ e $\mathrm{PB}$, utilizando o quadro teórico de Princípios e Parâmetros (CHOMSKY, 1982) e o da Teoria da Variação e Mudança (WEINREICH; LABOV; HERZOG, 1968). Assim, o trabalho fornecerá evidências do comportamento das línguas de sujeito nulo, permitindo enfatizar as diferenças entre estas e o PB.

Espera-se encontrar, no italiano e no espanhol, um comportamento mais semelhante ao do PE, língua de sujeito nulo (LSN). A análise permitirá determinar que fatores atuam no favorecimento do preenchimento do sujeito, supondo que esta seja a forma marcada no italiano e no espanhol.

A análise do espanhol foi feita com base em entrevistas de fala culta espanhola (de Madri) e argentina (de Buenos Aires), extraídas do CD-ROM organizado por Samper Padilla, Hernández Cabrera eTroya Déniz (1995), que contém amostras de 12 variedades do espanhol, gravadas nos anos 70 . A análise do italiano se baseia na fala culta extraída de Cresti e Moneglia (2005), um DVD que apresenta significativa amostra de línguas românicas européias (português, francês, italiano e espanhol) nas modalidades oral e escrita. Para garantir a comparabilidade dos nossos resultados com os obtidos para PE e PB (DUARTE, 1995), os dados foram codificados segundo variáveis linguísticas e sociais e submetidos ao VARBRUL (PINTZUK, 1988).

\footnotetext{
${ }^{1} \mathrm{O}$ italiano standard é o sistema linguístico diretamente derivado do dialeto florentino do século XIV, adotado como língua nacional.

${ }^{2}$ Considera-se "fala culta" a dos indivíduos que possuem ensino superior completo ou incompleto.
} 


\section{PB: sistema em mudança}

\subsection{Mudança na marcação do PSN: perspectiva diacrônica}

Duarte (1993), examinando peças teatrais dos séculos XIX e XX, apresenta indícios de mudança paramétrica no sentido do preenchimento. Esse processo seria consequência do enfraquecimento da morfologia verbal (DUARTE, 1993; 1995; 2003), devido às mudanças efetivadas no quadro pronominal.

A Figura 1, adaptada de Duarte (1993), mostra a progressiva redução no percentual de sujeitos nulos:

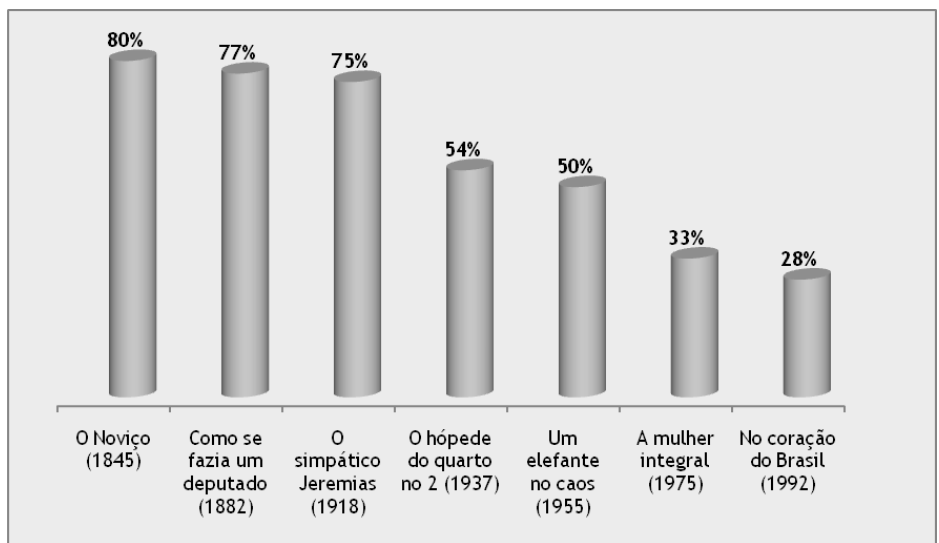

Figura 1 - Sujeito nulo nas peças teatrais dos séculos XIX e XX

No grá fico acima, podemos identificar dois momentos em que houve redução significativa no percentual de sujeitos nulos: o primeiro, a partir da terceira década do século XX, e o segundo, no último quarto do mesmo século. Essa situação pode ser explicada pela relação entre mudança do sistema pronominal, enfraquecimento da morfologia verbal e identificação do sujeito nulo. A autora observou que, nas três primeiras peças, o paradigma flexional do verbo era constituído de seis oposições, ou seja, era 
“formalmente rico" (JAEGGLI; SAFIR, 1989), o que garantiria a identificação do sujeito nulo. Por isso, o gráfico revela preferência pela não expressão do sujeito, com percentuias acima de $75 \%$, mostrando que o PB se comportava como LSN.

Nas duas peças seguintes, a redução de sujeitos nulos estaria ligada à neutralização das formas distintivas no paradigma flexional do verbo, promovida pela substituição dos pronomes tu e vós por você e vocês. Assim, o número de oposições na morfologia verbal teria passado de seis para quatro, dada a presença de dois sincretismos no paradigma: o morfema $\varnothing$, para a segunda e a terceira pessoas do singular, e -m, compartilhado pela segunda e terceira do plural. Com isso, segundo Duarte (1993), o paradigma começa a mostrar erosão, o que denuncia o início da mudança.

As peças dos últimos 25 anos do século XX evidenciam que o comportamento do sujeito no $\mathrm{PB}$, em relação ao século XIX, já não é o mesmo. A entrada da forma a gente (em competição com nós, cada vez menos frequente na fala) teria feito com que fosse ultrapassado o limite de dois sincretismos estabelecido por Duarte (1993) como máximo para que uma língua possa identificar/licenciar o sujeito nulo. Assim, o paradima flexional do verbo no PB deixa de ser "funcionalmente rico" (ROBERTS, 1993), provocando, então, preferência pela expressão do sujeito, como vemos nas duas últimas colunas do gráfico, em que o percentual de sujeitos nulos é bastante baixo (33\% e 28\%).

\subsection{Sintomas da mudança na fala: perspectiva sincrônica}

Para buscar evidências empíricas que confirmassem o processo de mudança no comportamento do sujeito pronominal de referência definida no PB atual, Duarte, em estudos sobre a fala culta (1995) e a popular (2003), atesta a preferência pelo pronome pleno em todas as pessoas gramaticais, com a terceira demonstrando maior resistência ao preenchimento. Isso significa que mesmo a primeira pessoa, que apresenta desinência exclusiva, tende a ser mais realizada por meio de pronome expresso. Ou seja, os sujeitos identificados por flexão verbal são os que apresentam 
maior suscetibilidade ao preenchimento, evidenciando que o sistema vem perdendo a capacidade de identificar o sujeito nulo. Por outro lado, os identificados pelo contexto são os mais resistentes. Assim, o caráter dêitico dos pronomes de primeira e segunda pessoas faz com que sejam mais expressos que os pronomes de terceira pessoa, cuja interpretação é garantida por um antecedente.

Cyrino, Duarte e Kato (2000), com base em tais evidências, propõem uma hierarquia de referencialidade que atua nos processos de mudança envolvendo pronomes. No caso do preenchimento, os itens mais referenciais seriam os primeiros a ser preenchidos. A primeira e a segunda pessoas, com o traço inerentemente [+ humano], estariam em um dos extremos desse contínuo; a terceira, que abriga elementos com traços [+/- humano], [+/- animado], [+/- específico], estaria em um ponto mais à esquerda do contínuo, sendo mais resistente.

A relação entre a identificação do sujeito nulo e seu referente é reforçada pelo fato de que, segundo Duarte, a não expressão do sujeito tende a ser maior quando seu referente está na oração anterior e também é sujeito, confirmando que o "grau de conexão discursiva" (PAREDES SILVA, 1988) interfere no comportamento do sujeito pronominal:

(1) A senhora falou que não gosta de cozinhar e que tinha empregada.

Assim, quando há manutenção do referente do sujeito, é maior a possibilidade de que seja nulo. Em contrapartida, com mudança do referente, é maior a probabilidade de que seja expresso:

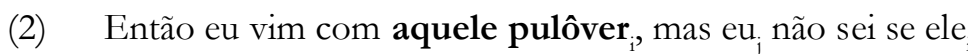
'tá bonito, se ele ${ }_{\mathrm{i}}$ 'tá combinando. (DUARTE, 1995)

Outro ponto importante no que se refere ao favorecimento do sujeito pleno no PB é a função de oração: aquelas que apresentam elemento em SpecCP (relativas, adverbiais e 
interrogativas) tendem a apresentar um pronome expresso na posição de sujeito. As orações com elemento no núcleo de $\mathrm{CP}$, como (1), ainda exibem sujeito nulo de terceira pessoa, e aquelas com $\mathrm{CP}$ vazio se mostram mais resistentes à mudança.

Como consequência do processo de mudança em curso, Duarte (1995) mostra a emergência de estruturas com sujeitos deslocados à esquerda. Essas estruturas não ocorrem em LSN, como PE (DUARTE, 1987), espanhol (RIVERO, 1980) e italiano (DURANTI; OCHS, 1979), mas são altamente frequentes no francês (BLANCHE-BENVENISTE, 1993), língua de sujeito não nulo (LSNN).

A observação do comportamento das três faixas etárias que compõem a amostra sugere mudança em tempo aparente, mostrando as diferenças entre a fala dos mais velhos - em que o sujeito nulo ainda resiste - e a dos mais jovens - em que a mudança alcança seu ápice. Dessa forma, Duarte (1995) confirma sincronicamente o que já havia sido indicado no estudo diacrônico (DUARTE, 1993): o PB atual não manteve as características de língua [+ sujeito nulo] do fim do século XIX e início do XX, assumindo propriedades de língua [- sujeito nulo].

\section{Confronto entre PE e PB}

As afirmações feitas por Duarte $(1993 ; 1995 ; 2003)$ sobre a mudança na marcação paramétrica no PB se tornam ainda mais contundentes quando observamos o comportamento do sujeito pronominal em outras línguas, como o PE (DUARTE, 1995).

Em contraste com o que foi encontrado para o PB, o PE exibe um paradigma flexional funcionalmente rico, o que, como vimos (ROBERTS, 1993; DUARTE, 1995), garante o licenciamento e a identificação do sujeito nulo. Isso é atestado pela autora ao encontrar uma expressiva preferência pela não realização do sujeito em todas as pessoas gramaticais na fala lusitana. Chama a atenção o fato de a primeira pessoa, mesmo majoritariamente nula, apresentar os maiores índices de preenchimento (como no $\mathrm{PB}$ ), conforme o Quadro 1, adaptado de Duarte (1995): 


\begin{tabular}{|l|c|c|}
\hline Pessoa gramatical & Ocorrências & $\mathbf{\%}$ \\
\hline 1 $^{\text {a }}$ singular & $248 / 421$ & $59 \%$ \\
\hline 1 $^{\text {a }}$ plural & $86 / 140$ & $61 \%$ \\
\hline $2^{\text {a }}$ singular & $82 / 110$ & $75 \%$ \\
\hline $2^{\text {a }}$ plural & $19 / 28$ & $68 \%$ \\
\hline $3^{\text {a }}$ singular & $205 / 285$ & $72 \%$ \\
\hline $3^{\text {a }}$ plural & $98 / 132$ & $74 \%$ \\
\hline Total & $738 / 1116$ & $66 \%$ \\
\hline
\end{tabular}

Quadro 1 - Percentuais de sujeitos nulos por pessoa gramatical no PE

Tal fato pode ser explicado, de acordo com Duranti e Ochs (1979), pela tendência que o falante tem de se introduzir no discurso com pronome lexicalmente expresso. Essa seria uma estratégia discursiva comum às línguas de modo geral. Ainda assim, é bastante expressivo o percentual de sujeitos nulos, se levarmos em conta os resultados para o $\mathrm{PB}$.

Sobre a segunda pessoa, não foram encontradas diferenças substanciais quanto à expressão do sujeito entre as formas direta (tu) e indireta (você): ambas apresentam altos índices de sujeitos nulos. Isso possibilita afirmar que a desinência distintiva não afeta a representação do sujeito. Os exemplos (3) e (4), de Duarte (1995), mostram a desinência $\varnothing$, compartilhada pela segunda pessoa indireta você e a terceira do singular, associada a sujeitos nulos:

(3) Por exemplo, nesse trabalho que __ apresentou sobre poesia, __ é capaz de me dizer o que __ aproveitou do contato com os alunos?

(4) [...] agora não há dúvida nenhuma que se for de facto um indivíduo responsável na produção, tem de se incomodar porque não é apoiado naquela parte de stocks de existências, de fornecimento, etc. 
Sobre a terceira pessoa, tem-se como relevante a animacidade de seu referente. $\mathrm{O}$ traço [- animado] apresenta um percentual de 93\% de sujeitos nulos, ao passo que o traço [+ animado] apresenta índice de 69\%, revelando-se menos restrito à retomada por um pronome lexicalmente expresso.

De todo modo, a análise do comportamento das pessoas gramaticais permite confirmar a hierarquia de referencialidade proposta por Cyrino, Duarte e Kato (2000), já que há maior resistência da terceira pessoa ao preenchimento em relação às outras.

Quanto ao tipo de oração, Duarte constatou que somente as relativas no PE apresentam índices expressivos de preenchimento na primeira e na terceira pessoas $(70 \%$ e $61 \%$, respectivamente). Tal fato se deve à acessibilidade do referente do sujeito: a maioria dos sujeitos das orações relativas encontradas têm referentes com outra função sintática na matriz ou se encontram em uma oração anterior à matriz, conforme mostram os exemplos em (5) e (6), extraídos de Duarte (1995):

(5) [...] mas nós é que estamos sempre a dar explicações ao público $_{i}$, que ele ${ }_{i}$ por vezes já não aceita.

(6) Os bombeiros são geralmente poucos. Os montes muitas vezes não têm estradas que eles ${ }_{i}$ possam... que eles possam $_{1}$ facilmente acercar-se do fogo.

Num caso como (6), havendo mais de uma possibilidade de coindexação, o pronome pleno é a estratégia adotada para garantir sua interpretação como sendo a do referente mais distante (CALABRESE, 1986). Nos casos em que o sujeito da relativa e o da matriz são correferenciais, a estratégia é a não expressão do sujeito, como em (7):

(7) $\mathbf{O}$ corredor ${ }_{\mathrm{i}}$ vive as corridas desde o primeiro dia que chega.

Fatores extralinguísticos não foram apontados como relevantes na análise do PE, colaborando para confirmar a 
estabilidade do sistema no que se refere ao seu caráter de LSN.

\section{O que nos diz o espanhol}

Dentro da mesma perspectiva teórico-metodologica de Duarte $(1995,2003)$, a análise de duas variedades [+ sujeito nulo] do espanhol (Madri e Buenos Aires) revelou que as falas madrilena, portenha e lusitana guardam entre si mais semelhanças que diferenças, o que já se verifica na questão da riqueza funcional: o espanhol não ultrapassa os dois sincretismos definidos como limite por Duarte (1995), o que licencia o apagamento do sujeito. Desse modo, verificou-se a preferência pela forma nula (73\% em Madri e $71 \%$ em Buenos Aires ${ }^{3}$ ) em detrimento da forma plena em todas as pessoas gramaticais, conforme o Quadro 2, adaptado de Soares da Silva (2006):

\begin{tabular}{|l|c|c|c|c|}
\hline Pessoa gramatical & Madri & P.R. & Buenos Aires & P.R. \\
\hline Yo & $336 / 517(65 \%)$ & .38 & $330 / 527(63 \%)$ & .46 \\
\hline Nosotros & $90 / 101(89 \%)$ & .75 & $40 / 65(62 \%)$ & .40 \\
\hline Tú & $113 / 144(78 \%)$ & .41 & $78 / 100(78 \%)$ & .44 \\
\hline Vosotros & $6 / 6(100 \%)^{4}$ & - & - & - \\
\hline Usted & $80 / 116(69 \%)$ & .23 & $101 / 168(60 \%)$ & .35 \\
\hline Ustedes & $6 / 9(67 \%)$ & .19 & $12 / 19(63 \%)$ & .26 \\
\hline Él/ella & $213 / 242(88 \%)$ & .71 & $208 / 258(81 \%)$ & .69 \\
\hline Ellos/ellas & $99 / 109(91 \%)$ & .76 & $65 / 84(77 \%)$ & .63 \\
\hline Total & $943 / 1244(76 \%)$ & & $834 / 1221(68 \%)$ & \\
\hline \hline
\end{tabular}

Quadro 2 - Percentual de sujeitos nulos pelas pessoas gramaticais no espanhol

\footnotetext{
${ }^{3}$ Esses índices se referem aos resultados gerais, incluindo os sujeitos plenos pospostos, retirados da análise posteriormente, já que expressão do sujeito nesses casos é obrigatória, cumprindo a tarefa de desfazer ambiguidades ou estabelecer contrastes.

${ }^{4}$ Para efeito de comparação entre as duas variedades e para que se pudesse proceder à análise da regra variável, os dados de segunda pessoa do plural do espanhol de Madri foram excluídos, dada sua categoricidade.
} 
Os resultados para a pessoa gramatical nas duas variedades são semelhantes: a primeira pessoa, assim como no PE, apresenta índices significativos de preenchimento, conforme previsto por Duranti e Ochs (1979). Em especial, no espanhol, a segunda pessoa indireta, tanto no plural quanto no singular, aparece desfavorecendo o sujeito nulo, como já havia apontado Fernández Soriano (1999), confirmando a conservação do caráter de tratamento do pronome usted(es). A diferença entre as duas variedades no que diz respeito à pessoa gramatical é o fato de que, apenas em Buenos Aires, quando a pessoa gramatical pode estar ligada tanto ao morfema $\varnothing$ como outro tipo de desinência, a expressão do sujeito é favorecida.

A animacidade do referente do pronome de terceira pessoa também constitui ponto de contato entre o espanhol e o PE: em ambos, o traço [- animado] favorece o apagamento do sujeito, ainda que não tenha sido encontrada nenhuma ocorrência de sujeito pleno com o traço [- animado] em nenhuma das duas variedades do espanhol, diferentemente do que ocorreu na análise do PE de Duarte (1995), em que se verificou uma marca de 7\% de sujeitos plenos com o traço [- animado]. Embora esse índice não seja significativo o suficiente para identificar o PE com línguas de sujeito pleno, isso sugere que o espanhol, quanto à animacidade do referente, apresenta um comportamento "mais genuinamente prodrop" do que o PE.

Quanto ao tipo sintático da oração, na fala portenha, as orações relativas mostraram-se, assim como no PE (DUARTE, 1995), desfavorecedoras do sujeito nulo: a posição de sujeito é preenchida quando seu referente tem função diversa da de sujeito e fica vazia quando o sujeito da relativa e o da matriz são correferentes. O sujeito nulo também é favorecido, em Madri, pelas orações interrogativas parciais, à semelhança do que ocorre no PE (neste, porém, as interrogativas, independentemente de ser parciais ou globais, favorecem o sujeito nulo), enquanto em Buenos Aires esse tipo de oração não se mostrou relevante no que se refere ao preenchimento.

Outro ponto de encontro entre espanhol e PE é o padrão sentencial atuando na acessibilidade do DP referente do pronome 
sujeito. Assim como para o PE, para o espanhol notou-se que, se o DP tem uma função sintática diferente de sujeito ou há material interveniente entre o DP e o pronome, a tendência ao preenchimento é maior. Contudo, o comportamento é levemente diferente entre as duas variedades do espanhol: enquanto em Madri os sujeitos plenos realizados em contextos em que seu referente pode ser facilmente acessado - onde se espera que seja nulo indicam ênfase, contraste ou contraposição, em Buenos Aires há, em todos os contextos, variação entre sujeitos nulos e plenos. Essa diferença indica um comportamento mais prototipicamente compatível com LSN em Madri que em Buenos Aires.

A análise das faixas etárias em Madri e Buenos Aires revelou percentuais e pesos relativos aproximados, o que permite considerar que os sistemas não se encontram em processo de mudança.

$\mathrm{Na}$ comparação dos resultados entre $\mathrm{PB}, \mathrm{PE}$, espanhol europeu (EE) e espanhol argentino (EA), é nítida a distância da situação da representação do sujeito pronominal na fala brasileira em relação às demais. Todavia, o trabalho de Soares da Silva (2006) forneceu indícios de algumas diferenças entre $\mathrm{PE}$ e as variedades do espanhol estudadas, fazendo-nos crer que, embora as LSN apresentem as mesmas propriedades, não as exibem de maneira idêntica. Propôs-se, então, um continuum, variando do pólo [+ sujeito nulo] ao [- sujeito nulo], onde as línguas poderiam ser dispostas, conforme vemos na Figura 2, adaptada de Soares da Silva (2006, p. 106):

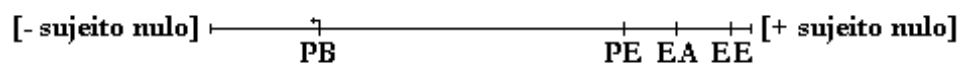

Figura 2 - Escala contínua para o Parâmetro do Sujeito Nulo 


\section{Análise do italiano}

Foram encontrados 965 dados de sujeito pronominal de referência definida, dos quais 98 (10\% do total) exibiam nuance contrastiva ou ênfase. Naturalmente, todos os dados de contraste e ênfase encontrados apresentam sujeito foneticamente realizado (RIZZI, 1982), antepostos ou pospostos ao verbo, como é possível observar em (8), em que mostramos os sujeitos contrastivos, e em (9), em que se constata ênfase:

(8) Ho detto: "no, IO sono individualista, TU invece sei egoista". [SND ifamcv21]

(eu) Disse: "não, eu sou individualista, você, ao contrário, é egoísta.

(9) LIA: [...] 'un [non] mi ricordo indo' ho messo le fotografie delle Dolomiti e della Germania. Oh, questa è bella. Eppure le presi...

ELA: Mi ricordo che TU me l'hai fatte vedere anche a me. [ELA ifamcr01]

LIA: Não me lembro onde coloquei as fotografias das Dolomitas e da Alemanha. Oh, essa é bonita. Também as tirei...

ELA: Me lembro que você as mostrou também a mim.

Além dos sujeitos contrastivos e enfáticos, esperávamos encontrar sujeitos categoricamente plenos quando a desinência número-pessoal do verbo favorece a ambiguidade, como ocorre no presente congiuntivo, em que se verifica a desinência $\varnothing$ para as três pessoas do singular, e no imperfeito congiuntivo, em que a primeira e a segunda pessoas do singular compartilham a desinência $\varnothing$. No entanto, não foram encontrados sujeitos plenos desambiguadores.

\subsection{Sujeitos nulos vs. plenos}

Do total de 867 dados computados para análise multivariada, 746 exibem sujeitos nulos (86\%) e 121, sujeito preenchidos (14\%). 
Desse modo, o italiano mostrou-se predominantemente favorável ao apagamento do sujeito.

Para estabelecer uma comparação com os resultados encontrados para as duas variedades do português, PE e PB (cf. DUARTE, 1995), e para as do espanhol, Madri e Buenos Aires (cf. SOARES DA SILVA, 2006), apresentamos a seguir o Quadro 3, com os resultados gerais para as línguas/variedades observadas:

\begin{tabular}{|l|c|c|c|}
\hline $\begin{array}{l}\text { Língua/Variedade } \\
\text { Românica }\end{array}$ & Nulos & Plenos & Total \\
\hline Italiano & $\mathbf{7 4 6 \mathbf { 8 6 } \% )}$ & $\mathbf{1 2 1} \mathbf{( 1 4 \% )}$ & $867(100 \%)$ \\
\hline Espanhol (Madrid) & $\mathbf{9 3 7} \mathbf{( 7 6 \% )}$ & $\mathbf{4 2 2} \mathbf{( 2 6 \% )}$ & $1359(100 \%)$ \\
\hline Espanhol (Buenos Aires) & $\mathbf{8 3 4}(\mathbf{6 8 \%})$ & $\mathbf{4 1 4}(\mathbf{2 1} \%)$ & $1248(100 \%)$ \\
\hline PE & $\mathbf{7 3 8 ( 6 6 \% )}$ & $\mathbf{3 7 8 ( 3 4 \% )}$ & $1116(100 \%)$ \\
\hline PB & $\mathbf{4 1 5 ( 2 9 \% )}$ & $\mathbf{1 0 0 9}(\mathbf{7 1} \%)$ & $1424(100 \%)$ \\
\hline
\end{tabular}

Quadro 3 - Distribuição de sujeitos nulos vs. plenos nas línguas românicas

Em uma primeira análise, é nítida a aproximação entre italiano, espanhol e PE, no que diz respeito à preferência pelo sujeito nulo, com índices superiores a $65 \%$. O PB revela percentual absolutamente expressivo de sujeitos plenos (71\%), comportamento diametralmente oposto ao das outras línguas/ variedades românicas.

De fato, assim como no espanhol e no PE, esperávamos encontrar, no italiano, sujeitos plenos, tendo em vista o Princípio do Subconjunto (RAPOSO, 1992), segundo o qual podemos compreender que línguas positivamente marcadas em relação ao PSN, apesar de exibirem a forma nula como default, podem (ou precisam) apresentar sujeitos foneticamente realizados. É o que afirma Rizzi (1982), sobre os casos de contraste e ênfase, além da desambiguização, e até mesmo da introdução do falante ou da retomada de um sujeito distante na mudança de tópico. 


\subsection{Sujeitos plenos no italiano}

Com a subtração dos casos de sujeitos categoricamente plenos, restam-nos 867 dados, dos quais $746(86 \%)$ são nulos e $121(14 \%)$, plenos. Apesar de os sujeitos plenos totais representarem uma parcela relativamente pequena, é necessário fazermos algumas considerações sobre os contextos discursivos em que se inserem os sujeitos foneticamente realizados em uma LSN.

O corpus utilizado para a constituição da amostra em análise é composto por conversações com mais de um participante. Nessas condições, constatamos situações particulares desse tipo de corpus, como: (a) introdução do participante na conversa, tanto no primeiro registro de sua presença, quanto em retomada de turno de fala, expressando opinião, ratificação ou reiteração de uma opinião/ idéia anterior; (b) referência direta a participantes, tanto em primeira menção quanto nos casos de mudança de interlocutor; e (c) introdução de um tópico discursivo.

Desse modo, foi possível verificar que todas as ocorrências de sujeitos plenos poderiam ser enquadradas num dos itens (a)(c), o que nos permite dizer que, dentre os dados analisados, a presença de um pronome sujeito anteposto ao verbo exibe outras funções discursivas, além das que já havíamos considerado.

\subsubsection{Desinência número-pessoal: problema da ambiguidade}

$\mathrm{Na}$ amostra analisada, não foram encontrados casos de pronome de segunda pessoa indireta $(L e \imath)$. Isso nos permitiu definir que, nessa amostra, trabalharíamos com desinências númeropessoais exclusivas e o morfema $\varnothing$ usado para duas (imperfeito congiuntivo) ou três (presente congiuntivo) pessoas gramaticais. No caso do morfema $\varnothing$, a presença de um pronome pleno seria uma estratégia para que se pudessem evitar ambiguidades.

Apenas cinco dados correspondem às formas verbais com desinência $\varnothing$. Estes apresentam apenas formas do presente congiuntivo, idênticas para as três pessoas do singular. Além disso, 
todos estão em orações encaixadas. Das cinco ocorrências, três encontram-se em completivas de verbos inacusativos (sembrare e parere), que não selecionam argumento externo, como exemplifica (10):

(10) SIL: Perché io lo $_{j}$ adoro quando praticamente lui fa la parte dell' imbarazzato, perché, secondo me, comunque lui $i_{i}$ era proprio cosí.

GIA: __ Fa sempre quella... ogni volta che __ parla, expl sembra che [__ sia imbarazzato], ogni volta che dice qualcosa. [GIA ifamcv12]

SIL: Porque en o adoro quando, de fato, ele faz a parte do atrapalhado, porque, na minha opinião, entretanto ele era assim mesmo.

GIA: (ele) Faz sempre aquela... cada vez que fala, parece que seja atrapalhado, cada vez que diz qualquer coisa.

Podemos observar que o sujeito da oração encaixada não poderia estar coindexado com o da matriz, cujo verbo não projeta argumento externo. Desse modo, só resta ao sujeito da encaixada estar coindexado com o sujeito da oração anterior. Essa circunstância inviabiliza a ambiguidade, mesmo se tratando de forma verbal homófona para as três pessoas do singular.

As outras duas orações completivas com verbos no presente congiuntivo, que ocupam a posição de argumento interno dos verbos de suas matrizes, não apresentam núcleo de $\mathrm{CP}$ preenchido, sendo justapostas. Vejamos o exemplo:

(11) LEO: _ _ Penso un panoramico $\ldots$

GNA: Forse __ ${ }_{k}$ non $l_{j}$ trovi, fa nulla.

LEO: Cosa?

GNA: __ Non so se si trova__; perché io ${ }_{i}$ penso __ _ sia poco. È tanto, sì, ma io ${ }_{i}$ penso __ sia poco, certo... [GNA ifamcv02]

LEO: Penso um panorâmico...

GNA: Talvez (você) não o encontre, sem problemas.

LEO: O quê? 
GNA: Não sei se se encontra, porque eu penso (que) seja pouco. É muito, sim, mas eu penso (que) seja pouco, certo...

O verbo essere, na forma do presente congiuntivo (sia) das duas orações completivas, poderia estar, teoricamente, levando em consideração apenas os aspectos estruturais e, portanto, desprezando momentaneamente as questões semânticas, coindexado com o sujeito da oração matriz (io), com o sujeito da oração na fala anterior do informante $(t u)$ e com um terceiro elemento, como é o caso, tópico do discurso, complemento de pensare e trovare, nas falas de LEO e GNA, respectivamente, tendo em vista a questão da desinência número-pessoal Ø. Entretanto, é necessário observar algumas propriedades da subordinação em italiano.

A primeira consideração a ser feita é que, segundo Dardano e Trifone (2003), orações encaixadas na posição de argumento interno da matriz, em italiano, apresentam verbos no modo congiuntivo sempre que o verbo da oração matriz denotar "vontade, desejo, expectativa ou temor". Todavia, assim como em português, o italiano dispõe desse tipo de oração com (a) complementizador (que pode vir omitido, como ocorre no exemplo acima) e verbo finito (na tradição gramatical italiana: forma esplicita) e (b) oração infinitiva (forma implicita), que deve ser introduzida pela preposição di. Sobre o uso de uma ou outra forma, os autores afirmam:

A objetiva reduzida é introduzida pela preposição 'di' [...] e tem um verbo no infinitivo, com o mesmo sujeito da principal: [...]. É necessária, entretanto, a forma desenvolvida quando o sujeito for diferente $[\ldots]$

Logo após, continuam a explicação:

Com os verbos comandar, ordenar, permitir, proibir, vetar, pedir e outros com significado análogo, pode ocorrer a forma reduzida mesmo que o sujeito da principal e o sujeito da objetiva não coincidam [...] 
Retornando a (10), podemos constatar que, qualquer que fosse o contexto discursivo, levando em conta a o verbo da oração matriz e o fato de que a encaixada é esplicita (ainda que justaposta), não haveria a possibilidade de coindexação entre os sujeitos da matriz e da encaixada, pois deveríamos ter a forma implicita, como no exemplo (12), retirado de Dardano e Trifone (2003):

$$
\underset{\text { Considero ter agido corretamente. }}{\longrightarrow} \text { Ritengo di }
$$

O que há é a coindexação entre o sujeito nulo da oração encaixada com o argumento interno da oração anterior, garantindo sua interpretação referencial e impossibilitando qualquer tipo de ambiguidade, sem que seja necessário realizar foneticamente o pronome sujeito.

\subsubsection{Animacidade do referente do pronome de terceira pessoa}

Conforme esperado, nenhum dado apresentou pronome expresso com referente [- animado], comportamento prototípico de LSN. Esse resultado evidencia ainda mais o afastamento do PB do rol das LSN, já que expressa foneticamente o sujeito nesses casos. Vejamos o Quadro 4:

\begin{tabular}{|l|c|c|c|}
\hline Animacidade & Nulo & Pleno & Total \\
\hline$[-$ animado $]$ & $\mathbf{1 1 7} \mathbf{( 1 0 0 \% )}$ & - & $117(100 \%)$ \\
\hline [+ animado $]$ & $\mathbf{2 8 8 ( 9 2 \% )}$ & $\mathbf{2 4} \mathbf{( 8 \% )}$ & $312(100 \%)$ \\
\hline Total & $\mathbf{4 0 5 ( 9 4 \% )}$ & $\mathbf{2 4} \mathbf{( 6 \%} \%)$ & $429(100 \%)$ \\
\hline
\end{tabular}

Quadro 4 - Distribuição de sujeitos nulos e plenos pelo traço semântico do referente 
O resultado apresentado mostra que a fala culta italiana encontra-se mais próxima do espanhol - a variedade madrilenha apresenta um percentual total de nulos de $92 \%$, seguida pela portenha, com 86\% de nulos (SOARES DA SILVA, 2006) -, em que não houve expressão do sujeito pronominal com referente [- animado], que do PE, que apresentou 7\% de sujeitos plenos com tal animacidade (DUARTE, 1995). Entretanto, o italiano revelou índices mais altos de sujeitos nulos que as duas variedades do espanhol, no que diz respeito aos sujeitos com traço [+ animado]. No Quadro 5 podemos ver os índices de sujeitos nulos nas variedades românicas comparadas:

\begin{tabular}{|c|c|c|}
\hline Língua/Variedade & [+ animado] & Total \\
\hline Italiano & $288(92 \%)$ & $312(100 \%)$ \\
\hline Espanhol (Madrid) & $309(88 \%)$ & $354(100 \%)$ \\
\hline Espanhol (Buenos Aires) & $273(78 \%)$ & $348(100 \%)$ \\
\hline $\mathrm{PE}$ & $238(69 \%)$ & $346(100 \%)$ \\
\hline $\mathrm{PB}$ & $138(36 \%)$ & $384(100 \%)$ \\
\hline
\end{tabular}

Quadro 5 - Sujeitos pronominais nulos com traço [+ animado] nas variedades românicas

O quadro sugere uma gradação que nos permite atestar o afastamento do PB das outras línguas, expressando maior preferência pelo preenchimento, e o diferente comportamento das LSN quanto à presença de sujeitos plenos. Apesar de italiano, espanhol e PE terem índices de sujeitos nulos muito mais significativos que os de sujeitos plenos, na comparação entre as línguas/variedades, os percentuais de nulos decrescem do italiano ao PE.

\subsection{Análise de regra variável}

Nesta seção, faremos comentários sobre os três grupos de fatores mais relevantes, segundo a análise estatística, para o 
aparecimento mais expressivo dos sujeitos nulos no italiano, na ordem apontada pelo VARBRUL.

\subsubsection{Pessoa gramatical}

A pessoa gramatical foi o fator mais relevante para a distribuição entre sujeitos nulos e plenos na amostra de italiano utilizada. O Quadro 6 mostra as porcentagens para cada pessoa:

\begin{tabular}{|l|c|c|}
\hline Pessoa gramatical & Ocorrências & P.R. \\
\hline $1^{\mathrm{a}}$ & $213 / 280(\mathbf{7 6} \%)$ & .37 \\
\hline $2^{\mathrm{a}}$ & $\mathbf{1 2 9 / 1 5 9 ( 8 1 \% )}$ & .44 \\
\hline $3^{\mathrm{a}}$ & $\mathbf{2 8 8 / 3 1 2 ( \mathbf { 9 2 } \% )}$ & $\mathbf{. 6 4}$ \\
\hline Total & $630 / 751(84 \%)$ & \\
\hline
\end{tabular}

Quadro 6-Nulos por pessoa gramatical

O quadro confirma nossas expectativas, exibindo hierarquia entre as pessoas gramaticais. A terceira pessoa aparece como a mais favorecedora do sujeito nulo (.64), claramente distante das duas demais: a segunda com índice de .44 (diferença de .20) e a primeira, com .37 (diferença de .27).

Como já descrito, os sujeitos plenos encontrados no italiano revelam algum tipo de ligação com aspectos pragmático-discursivos motivados pelo tipo de inquérito. Tais aspectos estão diretamente relacionados às duas primeiras pessoas do discurso. Essa observação, no tocante à primeira pessoa, está de acordo com a hipótese de Duranti e Ochs (1979), que mostram que o falante tende a se introduzir no discurso através do pronome pleno. Parece que o mesmo ocorre com a segunda pessoa: o falante tende a introduzir o seu interlocutor no discurso através do uso de um pronome pleno.

Esses resultados nos permitem dizer que, mesmo em LSN, a presença de sujeitos plenos se efetiva e também é influenciada 
pela referencialidade da pessoa gramatical. Esse fator se mostrou também relevante nas análises do PE (DUARTE, 1995) e das duas variedades do espanhol (SOARES DA SILVA, 2006), em um polo, e na do PB (DUARTE, 1995, 2003), em outro, sugerindo que a pessoa gramatical atua na representação do sujeito pronominal nas línguas que permitem um sujeito nulo ou expresso.

\subsubsection{Padrão sentencial}

O padrão sentencial foi o segundo grupo de fatores a ser selecionado como relevante para a representação do sujeito pronominal. O Quadro 7 mostra os percentuais e os pesos relativos encontrados para os padrões, ilustrados de (13) a (17):

\begin{tabular}{|c|c|c|}
\hline Padrão sentencial & Ocorrências & P.R \\
\hline Padrão A (13) & 49/54 (91\%) & .60 \\
\hline Padrão B (14) & $200 / 217(92 \%)$ & .65 \\
\hline Padrão C (15) & $47 / 51(94 \%)$ & .68 \\
\hline Padrão D (16) & $285 / 365(78 \%)$ & .40 \\
\hline Padrão E (17) & $25 / 30(83 \%)$ & .38 \\
\hline Padrão F & $24 / 34(71 \%)$ & .34 \\
\hline Total & $630 / 751(84 \%)$ & \\
\hline
\end{tabular}

Quadro 7 - Sujeitos nulos pelos padrões sentenciais

(13) Questo è il giorno che ho scoperto che ero cattivo. [MAX ifamcr01]

Esse é o dia que (eu) descobri que (eu) era malvado.

(14) Eh, Eno ${ }_{i}$ è questo qui. E qui quanto c'aveva, Massimo? [ELA ifamcv01]

Eh, Eno é esse aqui. E aqui, quanto (ele) tinha [de idade], Massimo? 
(15) guardi le fotocopie $e_{i}$, perchè __ _ son le stesse cose che dice lui a lezione [VAL ifamcv27]

(você) olha as fotocópias, porque (elas) são as mesmas coisas que dizele na aula.

(16) [...] cioè, uno vede degli scorci di quello [che c' è all'interno]. Può essere incuriosito. [LUI ifamcv16]

[...] ou seja, alguém vê os dos lados daquilo que bá no interior. Pode ficar curioso.

(17) Io ho avuto un professore bravissimo de fisica. Ho fatto fisica per tutti e cinque gli anni, perchè facevo la sperimentazione. Quindi, si fa fisica sempre. [...] E lui $i_{\mathrm{i}}$ era veramente, veramente bravo. [ALE ifamcv23]

Eu tive um professor ótimo de física. Fiz física durante todos os cinco anos, porque (eu) fazia a experiência. Assim, se far física sempre. E ele era realmente, realmente bom.

Conforme nossas expectativas, ainda que todos os padrões mostrem elevados percentuais de sujeitos nulos, os contextos em que o referente é mais facilmente encontrado, por estar no mesmo período $(\mathbf{A})$, ou no período imediatamente anterior $(\mathbf{B})$, tendem a favorecer o sujeito nulo. Até mesmo no caso de o antecedente exercer outra função sintática na oração anterior $(\mathbf{C})$ o sujeito nulo favorecido, um comportamento esperado numa LSN, que já foi perdido no PB. Isso se verifica com a observação dos pesos relativos dos padrões A, B e C: .60, .65 e .68, respectivamente. Os padrões $\mathbf{D}$ e $\mathbf{E}$ apresentaram pesos significativamente menores (.40 e .38, respectivamente), o que demonstra que a presença de material interveniente entre o sujeito pronominal e seu referente atua em favor do preenchimento.

A hierarquia encontrada na análise do italiano se verificou também no PE (DUARTE, 1995) e nas duas variedades do espanhol. Também no PB podemos observar um comportamento parecido, apesar da preferência pela expressão fonética do sujeito, o que sugere que a atuação dos padrões sentenciais é semelhante em LSN e LSNN. 
O padrão $\mathbf{F}$, como esperado, apresentou o menor peso relativo (.34), visto que representa a primeira menção do sujeito pronominal.

\subsubsection{Faixa etária}

A faixa etária do informante foi selecionada em terceiro lugar como grupo de fatores mais relevante no favorecimento/ desfavorecimento do preenchimento do sujeito pronominal. Esse grupo também apresentou relevância na análise do PB. Entretanto, há diferenças marcantes entre $\mathrm{PB}$ e italiano. Observemos o Quadro 8:

\begin{tabular}{|l|c|c|}
\hline Faixa Etária & Ocorrências & P.R. \\
\hline Faixa A (18-25 anos) & $\mathbf{2 6 0 / 2 9 4 ~ ( 8 8 \% )}$ & $\mathbf{. 6 0}$ \\
\hline Faixa B (26-40 anos) & $\mathbf{1 4 7 / 1 8 7 ~ ( 7 9 \% )}$ & $\mathbf{. 4 2}$ \\
\hline Faixa C (41-59 anos) & $\mathbf{2 2 3 / 2 7 0 ~ ( 8 3 \% )}$ & $\mathbf{. 4 5}$ \\
\hline Total & $630 / 751(84 \%)$ & \\
\hline
\end{tabular}

Quadro 8- Sujeitos nulos pelas faixas etárias

As duas faixas etárias mais velhas (B e $\mathbf{C})$ apresentam os pesos relativos mais baixos, mostrando-se mais favoráveis ao preenchimento da posição de sujeito. Por outro lado, a faixa etária mais jovem, com peso relativo de .60, favorece ligeiramente o sujeito nulo em relação às demais. O exame dos percentuais reforça a grande semelhança no comportamento dos falantes.

Apesar de essa configuração poder estar ligada à distribuição irregular da amostra analisada, a hierarquia das faixas etárias confirma a estabilidade do sistema italiano com relação à representação do sujeito pronominal: os resultados não sugerem nenhum tipo de mudança em curso, assim como nas duas variedades do espanhol (SOARES DA SILVA, 2006) e no PE (DUARTE, 1995). 
No caso do PB, a faixa etária mais jovem foi a que mais se mostrou expressiva na tendência de preencher o sujeito, seguida da faixa intermediária. Os mais velhos mostraram os índices mais baixos de preenchimento, o que nos leva a crer, dentro de um estudo de tempo aparente, que o PB realmente está passando por um processo de mudança quanto ao PSN.

\section{Conclusão}

Tendo em vista que, na análise do italiano, outros grupos de fatores, como tipo sintático da oração, estrutura do CP, elementos entre specIP e I não foram selecionados, como ocorreu no espanhol, e sequer apresentaram percentuais que possam sugerir qualquer tipo de favorecimento da forma nula/plena do pronome sujeito, como ficou patente nas análises de PB e PE (DUARTE, 1995), podemos notar que a representação do sujeito pronominal na fala culta italiana parece ter comportamento mais estável, estando mais de acordo com as propriedades prototípicas de LSN, "superando" as duas variedades do espanhol e o PE. Ou seja, na escala contínua proposta por Soares da Silva (2006), o italiano estaria no polo mais à direita:

\section{[- sujeito nulo] PB}

Figura 3 - Escala contínua quanto ao caráter [+/- sujeito nulo] inclusão do italiano

\section{Referências}

BLANCHE-BENVENISTE, Claire. Quelques caractéristiques grammaticales des "sujets" employés dans le français parlé des conversations. 1993. (mimeo.)

CALABRESE, Andrea. Pronomina: some properties of the Italian pronominal system. MIT Working Papers in Linguistics, n. 8, p. 1-46, 1986. 
CHOMSKY, Noam. Lectures on Government and Binding. 2. ed. Dordrecht: Foris, 1982.

CRESTI, Emanuela; MONEGLIA, Massimo (Coords.). C-ORALROM - Integrated Reference Corpora for Spoken Romance Languages. Studies in Corpus Linguistics, Amsterdã/Filadélfia, v. 15, 2005.

CYRINO, Sônia; DUARTE, Maria; KATO, Mary. Visible subjects and invisible clitics in Brazilian Portuguese. In: KATO, Mary; NEGRÃO, Esmeralda (Coords.). Brazilian Portuguese and the null subject parameter. Frankfurt: Vervuert-IberoAmericana, 2000. p. 55-73.

DARDANO, Maurizio; TRIFONE, Pietro. A língua italiana. Bolonha: Zanichelli, 2003.

DUARTE, Inês. A construção de topicalização na gramática do português: regência, ligação e condições sobre movimento. 1987. Tese (Doutoradto em Linguística Portuguesa) -Universidade de Lisboa, Lisboa.

DUARTE, Maria. A evolução na representação do sujeito pronominal em dois tempos. In: PAIVA, Maria; DUARTE, Maria (Coords.). Mudança lingüística em tempo real. Rio de Janeiro: Contra Capa, 2003.

A perda do princípio "Evite Pronome" no português brasileiro. Campinas: UNICAMP, 1995.

Do pronome nulo ao pronome pleno: a trajetória do sujeito no português do Brasil. In: ROBERTS, Ian; KATO, Mary (Coords.). Português brasileiro: uma viagem diacrônica. Campinas: UNICAMP, 1993.

DURANTI, A.; OCHS, E. Left-dislocation in Italian conversation. Syntax and Semantics, Nova Iorque, v. 12, p. 377-415, 1979.

FERNÁNDEZ SORIANO, Olga. El pronombre personal: formas y distribuciones. Pronombres átonos y tónicos. In: BOSQUE, 
Ignacio; DEMONTE, Violeta. Gramática descriptiva de la lengua española: sintaxis básica de las clases de palabras. Madri: Espasa, 1999. p. 1209-1273.

JAEGGLI, Osvaldo; SAFIR, Kenneth. The Null Subject Parameter and Parametric Theory. In: . (Coords.) The Null Subject Parameter. Dordrecht: Kluwer, 1989. p. 1-44.

PAREDES SILVA, Vera. Cartas cariocas: a variação do sujeito na escrita informal. Rio de Janeiro: UFRJ, 1988.

PINTZUK, S. VARBRUL programs. 1988. (mimeo.)

RAPOSO, Eduardo. Teoria da gramática: a faculdade da linguagem. Lisboa: Caminho, 1992.

RIVERO, M. On Left-Dislocation and topicalization in Spanish. Linguistic Inquiry, n. 2, p. 363-393, 1980.

RIZZI, Luigi. Issues in Italian syntax. Dordrecht: Foris, 1982.

ROBERTS, Ian. Verbs and Diachronic Syntax. Dordrecht: Kluwer, 1993.

SAMPER PADILLA, José; HERNÁNDEZ CABRERA, Clara; TROYA DÉNIZ, Magnolia. Macrocorpus de la norma lingüística culta de las principales ciudades del mundo hispánico. Universidad de Las Palmas de Gran Canaria, 1995.

SOARES DA SILVA, Humberto. O Parâmetro do sujeito nulo: confronto entre o português e o espanhol. 2006.117p. Dissertação (Mestrado em Letras - Letras Vernáculas) - Universidade Federal do Rio de Janeiro, Rio de Janeiro.

WEINREICH, Uriel; LABOV, William; HERZOG, Marvin. Empirical foundations for a theory of language change. In: LEHMAN, W.; MALKIEL, Y. (Coords.) Directions for historical linguistics. Austin: University of Texas, 1968. p. 97-195. 